\title{
Effect of Carprofen Treatment Following Experimentally Induced Escherichia coli Mastitis in Primiparous Cows
}

\author{
F. Vangroenweghe,${ }^{1}$ L. Duchateau, ${ }^{1}$ P. Boutet ${ }^{2}$ P. Lekeux,${ }^{2}$ P. Rainard,${ }^{3}$ \\ M. J. Paape, ${ }^{4}$ and C. Burvenich ${ }^{1}$ \\ ${ }^{1}$ Milk Secretion and Mastitis Research Center, Department of Physiology-Biochemistry-Biometrics, \\ Faculty of Veterinary Medicine, Ghent University, Salisburylaan 133-9820 Merelbeke, Belgium \\ ${ }^{2}$ Département de Physiologie, Faculté de Médecine Vétérinaire, Université de Liège Sart-Tilman, \\ 4000 Liège, Belgium \\ ${ }^{3}$ Institut National de la Recherche Agronomique, Pathologie Infectieuse et Immunologie Centre de Tours-Nouzilly, \\ 37380 Nouzilly, France \\ ${ }^{4}$ Bovine Functional Genomics Laboratory, USDA, ARS, Beltsville, MD 20705
}

\begin{abstract}
Acute Escherichia coli mastitis is one of the major sources of economic loss in the dairy industry due to reduced milk production, treatment costs, discarded milk, and occasional fatal disease. Nonsteroidal antiinflammatory drugs (NSAIDs) are frequently used as adjunctive therapy to antibiotics. The objective of the current study was to evaluate the effect of carprofen treatment following infusion of Escherichia coli into the mammary glands of primiparous cows during the periparturient period. Severity of mastitis was scored based on the average milk production in the uninfected quarters on $d+2$ postinoculation and a clinical severity score. Carprofen was administered intravenously at 9 $\mathrm{h}$ postchallenge, when clinical signs of mastitis appeared. In previous work, efficacy of NSAIDs was mainly evaluated using clinical symptoms. In the present study, the effect of carprofen on innate immune response was also assessed by quantification of inflammatory mediators. All primiparous cows reacted as moderate responders throughout the experimental period. Primiparous cows were intramammarily inoculated with $1 \times 10^{4} \mathrm{cfu}$ of $E$. coli P4:O32 in 2 left quarters. Analysis of blood and milk parameters, including IL-8, complement component C5a, lipopolysaccharide-binding protein (LBP), soluble CD14, prostaglandin $\mathrm{E}_{2}$, and thromboxane $B_{2}$ was performed from $d 0$ to $d+6$ relative to intramammary inoculation. Rectal temperature in carprofen-treated animals was lower than in control animals at 3 and $6 \mathrm{~h}$ posttreatment. Treatment also restored the decreased reticulorumen motility that occurs during $E$. coli mastitis to preinfection levels faster than in control animals. Carprofen treatment resulted
\end{abstract}

Received February 22, 2005.

Accepted April 4, 2005.

Corresponding author: Christian Burvenich; e-mail: christian. burvenich@UGent.be. in an earlier normalization of the clinical severity score. Eicosanoid (prostaglandin $\mathrm{E}_{2}$ and thromboxane $\mathrm{B}_{2}$ ) production in milk tended to be inhibited by carprofen. No significant differences in the kinetic patterns of somatic cell count, IL-8, complement component C5a, LBP, and soluble CD14 were observed. In conclusion, carprofen treatment improved general clinical condition by effective antipyrexia and restoration of reticulorumen motility but did not significantly inhibit eicosanoid production. Carprofen treatment did not result in a significant decrease of chemotactic inflammatory mediators, IL-8 and C5a, and early innate immune molecules, sCD14 and LBP. Therefore, major modulatory effects from NSAID administration were not observed in this mastitis model, although a larger study might confirm some apparent trends obtained in the present results.

(Key words: primiparous cow, carprofen, Escherichia coli mastitis, moderate inflammation)

Abbreviation key: C5a = complement component 5a, $\mathbf{C O X}=$ cyclo-oxygenase, $\mathbf{H R}=$ heart rate, $\mathbf{L B P}=$ LPSbinding protein, NSAID = nonsteroidal anti-inflammatory drug, $\mathbf{P G E}_{\mathbf{2}}=$ prostaglandin $\mathrm{E}_{2}, \mathbf{P I H}=$ postinfusion hour, $\mathbf{R T}=$ rectal temperature, $\mathbf{S C D 1 4}=$ soluble CD14, TMB = tetramethylbenzidine, $\mathbf{T X B}_{2}=$ thromboxane $\mathrm{B}_{2}$.

\section{INTRODUCTION}

Production costs attributed to mastitis represent one of the largest economic losses to the dairy industry. Mastitis caused by coliform bacteria is responsible for a major portion of these losses, predominantly as the result of acute clinical disease, and is associated with animal welfare problems related to significant clinical severity, toxemia, pain, and occasional mortality. Coliform mastitis in cattle may be associated with systemic clinical disease, which occurs predominantly in the period immediately after calving (Hill, 1981; Wilesmith et al., 1986; Burvenich et al., 2003). Systemic signs 
include general depression, fever, tachycardia, inhibition of reticulorumen motility, and many nonspecific responses, such as neutropenia, followed by leucocytosis (Verheijden et al., 1983). Considerable losses in milk production may occur in cows suffering from Escherichia coli mastitis (Hill, 1981; Lohuis et al., 1989; Dosogne et al., 1997; Hoeben et al., 2000). Inhibition of reticulorumen motility is a frequent consequence of $E$. coli mastitis (Verheijden et al., 1983) and results in perturbation of microbial degradation of ingested feed and may contribute to decreased milk production. Moreover, the marked decreases in plasma tyrosine levels that occur (Vandeputte-Van Messom et al., 1987) are not directly related to peak fever.

The pathophysiology of $E$. coli mastitis is characterized by the presence of endotoxin or LPS in the outer membrane of the etiological bacteria. Lipopolysaccharide is a proinflammatory molecule that is shed from the bacterial surface during bacterial replication or death (Burvenich et al., 2003). Clinical signs following experimentally induced $E$. coli mastitis are attributed to mediator shock rather than to endotoxin shock, because endotoxin mainly plays a local role (Hoeben et al., 2000; Dosogne et al., 2002). Several of the proinflammatory cytokines that mediate the localized and systemic response to gram-negative mastitis, including IL- $1 \beta$, IL6 , IL-8, and tumor-necrosis factor- $\alpha$, are upregulated by LPS (Shuster et al., 1993; Guha and Mackman, 2001). Binding of LPS to cell membranes also activates the membrane-bound enzyme, phospholipase A2, liberating arachidonic acid, which can be metabolized by 2 major enzyme systems, cyclo-oxygenase (COX) and lipoxygenase. The prostaglandins, prostacyclin and thromboxanes, are the products of the COX pathway, whereas the leukotrienes are synthesized following lipoxygenase enzyme activity. The eicosanoids are important mediators and modulators of inflammation, and play a role in the mediation of acute inflammation (Anderson, 1989; Rose et al., 1989). Intracerebroventricular injection of 50 to $200 \mu \mathrm{g}$ of prostaglandin $\mathrm{E}_{2}\left(\mathbf{P G E}_{\mathbf{2}}\right)$ in lactating goats elicited fever in normal lactating goats, the rise and fall being accompanied respectively by a decrease and an increase of mammary blood flow (Burvenich et al., 1982). Pretreatment with flurbiprofen (administered intracerebroventricularly) inhibited fever and changes in heart rate (HR) following experimentally induced LPS mastitis, but had little effect on the $\mathrm{Cl}^{-}$concentration in the affected mammary gland. Nevertheless, the first peak in the mammary blood flow curve occurred with some delay, whereas the second peak was clearly decreased (Burvenich, 1985). Intravenous pretreatment with flurbiprofen abolished fever and delayed the changes in milk ion concentration (Burvenich et al., 1989). It has also been shown that the release of plasma cortisol after intravenous LPS administration is partially controlled by prostaglandins (Massart-Leën et al., 1992).

Nonsteroidal anti-inflammatory drugs (NSAID) with antipyretic, analgesic, and anti-inflammatory activities, have been used as adjunctive or alternative therapy to systemic or intramammary antibiotics (Shpigel et al., 1994). Nonsteroidal anti-inflammatory drugs have been reported to alter the clinical course of $E$. coli or endotoxin-induced mastitis in the bovine. A distinct difference has to be made between their potential antipyretic and antiphlogistic activities. Various NSAIDs have different physicochemical characteristics, which result in unequal tissue distribution throughout the body and cause variations in pharmacokinetics, efficacy, and toxicity among species (Brune, 1990). In addition, the mechanism of action of NSAIDs may vary by selective inhibition of the synthesis of a particular class of prostaglandins and endoperoxides and by inhibition of biochemical reactions, in addition to COX inhibition (Kopcha and Ahl, 1989; Kopcha et al., 1992).

Cyclo-oxygenase has 2 isoforms, COX-1, which is constitutively expressed in most tissues and is responsible for maintenance of various physiological processes, such as normal body temperature; and inducible COX2 , a proinflammatory enzyme. Induction of COX-2 synthesis is stimulated by several cytokines (IL-1, tumornecrosis factor- $\alpha$ ), growth factors, and LPS (Lees et al., 2000). Most veterinary NSAIDs in current use are nonselective COX-1 and COX-2 inhibitors. It was recently demonstrated in a rat model of inflammation that the acute early peak expression of COX-2, which was proinflammatory, was followed by a second, larger increase of COX-2 expression, being anti-inflammatory (Gilroy et al., 1999). There is considerable interest in the development of specific COX-2 inhibitors for therapeutic use. However, interspecies variability in COX selectivity with regard to veterinary medicine can be enormous. The COX antagonists currently used in veterinary medicine are all regarded as nonspecific inhibitors of COX-1 and 2, with similar potencies against both enzymes, or even some selectivity for COX-1 inhibition (Lees et al., 2000). Until now, COX selectivity of carprofen in cattle remains unknown. However, in other species, carprofen COX selectivity was quite variable, from COX-1 specific in man, nonspecific in horses, and COX2 specific in dogs (Brideau et al., 2001).

The effects of NSAIDs have been studied in experimental coliform- and endotoxin-induced mastitis models. The NSAIDs have included flunixin meglumine (Anderson et al., 1986; Anderson, 1989; Lohuis et al., 1989), carprofen (Lohuis et al., 1991), flurbiprofen (Burvenich and Peeters, 1982; Vandeputte-Van Messom et al., 1987; Burvenich et al., 1989; Lohuis et al., 1989), 
ketoprofen (Ziv and Longo, 1991), ibuprofen (DeGraves and Anderson, 1993), indomethacine (Burvenich and Peeters, 1982), suprofen (Burvenich and Peeters, 1982), and meloxicam (Banting et al., 2000). In these studies, NSAIDs positively affected various clinical, hematological, biochemical, and pathophysiological parameters. Recently, ketoprofen, phenylbutazone, and dipyrone were shown to have beneficial effects in the treatment of field cases of clinical mastitis (Shpigel et al., 1994, 1996). However, these beneficial effects were claimed using NSAID treatment against a historical control group, which could raise questions with respect to a possible confusion between treatment effects and temporal effects. All NSAIDs in these studies were used as adjunctive therapy in combination with the administration of a systemic antibiotic, trimethoprim sulfonamide.

Carprofen $[( \pm)-6$-chloro- $\alpha$-methylcarbazole-2-acetic acid] is an NSAID that is well tolerated in the bovine (Ludwig et al., 1989). In healthy cows, carprofen is pharmacokinetically characterized by a small distribution volume $(0.09 \mathrm{~L} / \mathrm{kg})$, a relatively low systemic clearance $(2.4 \mathrm{~mL} / \mathrm{h}$ per $\mathrm{kg})$, and a long terminal half-life $(30.7$ h) (Lohuis et al., 1991). During an endotoxin-induced mastitic episode, systemic clearance decreased, whereas terminal half-life significantly increased (43.0 h). Following carprofen treatment at $2 \mathrm{~h}$ postchallenge, a significant reduction in severity of clinical parameters was observed.

A role for soluble CD14 (sCD14) and LPS-binding protein (LBP) in mediating bovine host responses to intramammary LPS or $E$. coli challenge has recently been demonstrated (Wang et al., 2002; Bannerman et al., 2003; Lee et al., 2003a,b). Following intramammary LPS infusion, sCD14 increases in milk (Bannerman et al., 2003; Lee et al., 2003a), paralleled by an increase in LBP (Bannerman et al., 2003). Moreover, sCD14 has been shown to sensitize the mammary gland to LPS (Wang et al., 2002) and to reduce the severity of experimental $E$. coli mastitis in mice (Lee et al., 2003c) and cows (Lee et al., 2003b). Interestingly, maximal levels of the chemoattractant IL-8 and complement component 5a (C5a) were observed before increases in either milk LBP or sCD14. This suggests that initial host cell activation can occur in the presence of basal levels of sCD14 and LBP (Bannerman et al., 2003; Vangroenweghe et al., 2004b). Furthermore, PMNL influx (as determined by SCC) occurred before increases in SCD14 and LBP, indicating that heightened levels of these molecules were not required for immediate host innate immune responses (Bannerman et al., 2003; Vangroenweghe et al., 2004b).

Until now, the few reports on the treatment of experimentally induced $E$. coli mastitis with NSAID have focused on the effects of these drugs on clinical symp- toms rather than biochemical parameters and eicosanoids. The objective of the present study was to examine the modulatory effect of carprofen treatment on different clinical, blood, and milk parameters following moderate inflammation in primiparous cows.

\section{MATERIALS AND METHODS}

\section{Experimental Animals and Study Facilities}

Experimental infections were approved by the Ethical Committee of the Faculty of Veterinary Medicine (Ghent University, Merelbeke, Belgium). The experimental infection was performed in a 2-mo period during spring, from April to June 2004. The study was conducted to good clinical practice standards under veterinary supervision and complied with applicable animal welfare and regulatory requirements. Provision for withdrawal of animals was based on predefined severity criteria. The treatment was blinded with respect to clinical observations and laboratory analyses. All primiparous cows $(n=25)$ were between 24 and 30 mo at calving. Cows arrived at the commercial dairy farm (Oudenaarde, Belgium) within $7 \mathrm{~d}$ after calving. The animals were on a system of zero grazing from arrival until the end of the inoculation trial and were fed twice daily at 0700 and $1700 \mathrm{~h}$. The ration consisted of corn silage, good quality hay, and water ad libitum. Concentrates (Sandilac; Dumoulin Voeders Sanders, Moorslede, Belgium) were distributed according to milk production.

Animals treated within $10 \mathrm{~d}$ before the intramammary inoculation were not included in the trial. Therefore, only healthy animals, free of major mastitis pathogens through 3 consecutive bacteriologically negative examinations, and with milk SCC below 100,000 cells/ $\mathrm{mL}$ on quarter basis were included for the intramammary E. coli challenge. Primiparous cows accepted for the intramammary challenge were inoculated between 12 and $28 \mathrm{~d}$ postparturition.

Milking was performed daily at 0800 and $1800 \mathrm{~h}$ using a quarter milking device (Packo and Fullwood, Zedelgem, Belgium). Daily quarter milk production, the yield of the evening and subsequent morning milking (expressed as L/d) was measured at $\mathrm{d}-7,-4,-1,0$, [postinfusion hour (PIH) 0 to 24], d 1 (PIH 24 to 48), d 2 (PIH 48 to 72), d 3 (PIH 72 to 96), and d 6 (PIH 144 to 168$)$.

\section{Inoculation Dose}

The generation time of $E$. coli in mammary secretions can be as short as 20 min (Petsch and Anspach, 2000; Burvenich et al., 2003). The primiparous cows were inoculated in their left quarters with $1 \times 10^{4}$ cfu of $E$. coli $\mathrm{P} 4: \mathrm{O} 32$. 


\section{Intramammary Inoculation Procedure}

Inoculation was performed as described previously (Hoeben et al., 2000). Briefly, E. coli P4:O32 (H37, $\beta$ glucuronidase+, hemolysin-), maintained as a stock in lyophilization medium at $-20^{\circ} \mathrm{C}$, was subcultured in brain-heart-infusion broth (CM225; Oxoid, Nepean, Ontario, Canada) at $37^{\circ} \mathrm{C}$ for 3 consecutive days and subsequently washed 3 times with pyrogen-free PBS and resuspended in PBS. Immediately before inoculation, the suspension was diluted in pyrogen-free PBS to a final concentration of $1 \times 10^{4} \mathrm{cfu} / \mathrm{mL}$. On d 0,30 min after morning milking (1.5 $\mathrm{h}$ after feeding), the cows were inoculated in the left front and rear quarters with a total volume of $10 \mathrm{~mL}$, consisting of $1 \mathrm{~mL}$ of inoculum and $9 \mathrm{~mL}$ of pyrogen-free saline solution ( $\mathrm{NaCl} 0.9 \%$; Baxter N.V., Lessines, Belgium) per quarter. All bacterial suspensions were infused into the teat cistern using a sterile, pyrogen-free teat cannula (length, $7 \mathrm{~cm}$, i.d., $2 \mathrm{~mm}$; Me.Ve.Mat, Deinze, Belgium). Before challenge, the teat ends were disinfected with $70 \%$ ethanol containing $0.5 \%$ chlorhexidine. After infusion, the bacterial suspension was thoroughly distributed into the udder cistern using a 30-s massage.

Following inoculation, a control sample of the inoculum was diluted, plated out on Columbia agar with $5 \%$ sheep blood (Biokar Diagnostics, Beauvois, France), and incubated for $24 \mathrm{~h}$ at $37^{\circ} \mathrm{C}$ to check for correct inoculum preparation and adequate inoculum dose administration at intramammary $E$. coli challenge.

\section{Treatment Protocol}

Carprofen, a powerful NSAID with unknown COX selectivity in the bovine, was administered intravenously into the jugular vein at PIH 9, when acute clinical symptoms (rectal temperature $>40^{\circ} \mathrm{C}$, quarter swelling, slightly abnormal milk appearance) were already present. Carprofen (1.4 mg/kg, Rimadyl; kindly provided by Pfizer Animal Health, Sandwich, UK) was administered according to BW (2.9 mL/100 kg). Control animals received saline solution $(0.9 \% \mathrm{NaCl}$; Baxter N.V., Lessines, Belgium) according to BW (2.9 mL/ $100 \mathrm{~kg})$.

\section{Sampling Procedure}

Blood and milk samples were collected on $\mathrm{d}-4, \mathrm{~d}-1$, $\mathrm{d} 0, \mathrm{~d}+1, \mathrm{~d}+2, \mathrm{~d}+3$, and $\mathrm{d}+6$ relative to the day of challenge. On the day of challenge, blood and milk samples were collected at PIH 3, 6, 9, 12, 15, 18, and 21.

Blood samples were drawn aseptically from the external jugular vein of each cow by venipuncture into evacuated tubes. Foremilk ( $5 \mathrm{~mL}$ ) was aseptically collected for diagnostic bacteriology for major pathogens before inoculation and for quantification of the population of $E$. coli (cfu) from PIH 3 onwards. Furthermore, milk samples (100 mL) were collected manually, using a method validated previously, for determination of SCC, milk composition, and the preparation of milk whey through centrifugation. All samples were kept on melting ice $\left(1^{\circ} \mathrm{C}\right)$ during transport and at the laboratory until analysis was performed or aliquots were prepared for freezing $\left(-20^{\circ} \mathrm{C}\right)$.

\section{Clinical Examination}

Classical clinical parameters were examined. Rectal temperature (RT), HR, respiration rate, reticulorumen motility, skin turgor, fecal appearance, appetite, general attitude, BCS (Edmondson et al., 1989), and aspects of the mammary gland [abnormal milk, swelling, temperature, pain, teat relaxation, and milk leakage (Table 1) (Massart-Leën et al., 1988)] were recorded at each blood and milk sampling time.

\section{Severity Determination and Clinical Severity Score}

The severity of $E$. coli mastitis was determined based on quarter milk production in the uninfected quarters at $\mathrm{d}+2$ postinfusion. Animals with quarter milk production in the uninfected quarters at $d+2$ higher than $50 \%$ compared with their quarter milk production on $\mathrm{d}-1$ in the same quarters were scored as moderate responders, whereas animals with a quarter milk production at $\mathrm{d}$ +2 lower than 50\% were considered severe responders (Vandeputte-Van Messom et al., 1993; Dosogne et al., 1997, 1999).

Clinical severity scoring was performed based on Wenz et al. (2001) with slight modifications (Table 2) (Vangroenweghe et al., 2004a,b). Clinical data (RT, skin turgor, reticulorumen motility, and general attitude) obtained from PIH 9 to 48 were scored, and based on their total score, primiparous cows were classified into mild, moderate, and severe responders.

\section{SCC and Milk Composition}

Somatic cell count was determined using a fluoroopto electronic method (Fossomatic 5000 cell counter; Foss Electric, Hillerød, Denmark) by the Milk Control Center (MCC, Lier, Belgium). Fat, protein, and lactose concentrations $(\mathrm{mg} / \mathrm{mL})$ were determined using midinfrared-photospectrometry (MilkoScan 4000; Foss Electric).

Milk samples were centrifuged at $1000 \times g(30 \mathrm{~min}$, $4^{\circ} \mathrm{C}$ ) for the determination of serum albumin $(\mathrm{mg} / \mathrm{dL})$, sodium $\left(\mathrm{Na}^{+}\right)$, chlorine $\left(\mathrm{Cl}^{-}\right)$, and potassium $\left(\mathrm{K}^{+}\right)$concentration $(\mathrm{mmol} / \mathrm{L})$. Fat was removed and samples of skim 
Table 1. Description of categorical parameters collected during examination of the mammary gland of primiparous cows at all time points when blood and milk samples are collected. Temperature, quarter swelling, pain, and teat relaxation were scored through manual palpation, whereas milk leakage and milk appearance were assessed through visual inspection.

\begin{tabular}{lll}
\hline Parameter & Score & Description \\
\hline Temperature & 0 & Normal \\
Quarter swelling & 1 & Abnormal: elevated to touch \\
& 0 & Normal: no swelling, udder pliable and light in weight \\
& 1 & Slight: udder less pliable with some firmness \\
Pain & 2 & Moderate: udder definitely firm and swollen \\
& 3 & Severe: udder very hard and heavy \\
Teat relaxation & 0 & Absent \\
& 1 & Present \\
Milk leakage & 0 & Absent \\
& 1 & Present \\
Milk appearance & 0 & Absent \\
& 1 & Present \\
& 0 & Normal \\
& 1 & Some flakes present \\
& 2 & More flakes or clots present, slightly watery \\
\hline
\end{tabular}

milk were immediately frozen at $-80^{\circ} \mathrm{C}$ until analysis. Serum albumin of thawed samples was quantified using a radial immunodiffusion kit (bovine low level albumin, Bethyl VET-RID; Bethyl Laboratories, Montgomery, TX). Briefly, $10 \mu \mathrm{L}$ of milk whey was added to each well and incubated at $20^{\circ} \mathrm{C}$ for $24 \mathrm{~h}$ before diameter of the radial immunodiffusion reaction was assessed. Squared diameters $\left(\mathrm{d}^{2}\right)$ were compared with a constructed standard curve of known amounts of serum albumin. Ion concentration was analyzed using an ion-selective electrode analyzer (Ilyte; Instrumentation Laboratories, Milan, Italy).

\section{Numbers of E. coli in Inoculated Quarters}

The number of $E$. coli (cfu/mL) after experimental inoculation was determined by appropriate 10-fold dilutions of each milk sample in PBS. Ten microliters of each dilution was plated on Columbia agar with $5 \%$ sheep blood (Biokar Diagnostics). All dilutions were performed in duplicate. Colonies were counted after a 24-h incubation at $37^{\circ} \mathrm{C}$. The colony count was converted to $\mathrm{cfu} / \mathrm{mL}$ based on the factor of dilution and finally expressed as $\log _{10} / \mathrm{mL}$ for statistical analysis.

\section{Packed Cell Volume and Blood Leukocyte Number}

Blood packed cell volume (\%) was determined in hematocrit capillaries (60 $\mu \mathrm{L} / 75 \mathrm{~mm}$; Hirschmann Laborgeräte, Eberstadt, Germany) using a microhematocrit centrifuge (Hawksley, London, UK). Blood leukocyte number $\left(\log _{10} / \mathrm{mL}\right)$ was determined using an electronic particle counter (Coulter Counter Z2; Coulter Electronics Ltd., Luton, UK).

\section{Determination of IL-8}

Milk IL-8 concentration was determined from undiluted whey samples assayed with a commercially available human IL-8 ELISA kit (R\&D Systems, Inc., Minneapolis, MN). The antibody pairs used in this kit have previously been shown to cross-react with bovine IL-8 (Shuster et al., 1996, 1997). Briefly, $100 \mu \mathrm{L}$ of milk whey sample was added to flat-bottomed microtiter plates, precoated with mouse monoclonal anti-IL-8 antibodies, and incubated for $1 \mathrm{~h}$ at $20^{\circ} \mathrm{C}$. Following washing, polyclonal anti-IL-8 antibodies conjugated to horseradish peroxidase were added and incubated $\left(1 \mathrm{~h}, 20^{\circ} \mathrm{C}\right)$. The substrate solution, tetramethylbenzidine (TMB; Sigma), was freshly prepared and added to each well following washing of the wells. After a 30-min incubation at room temperature, the reaction was stopped with $2 \mathrm{~N} \mathrm{H}_{2} \mathrm{SO}_{4}$. The optical density at $450 \mathrm{~nm}$ and a correction wavelength of $550 \mathrm{~nm}$ were measured on an automated microplate reader (BioKinetics Reader; BioTek Instruments, Winooski, VT). Values expressed in picograms per milliliter were extrapolated using linear regression from a standard curve of known amounts of human IL-8.

\section{Determination of $\mathbf{C 5 a}$}

Milk C5a was quantified by ELISA as previously described (Rainard et al., 1998). Briefly, flat-bottomed microtiter plates (Immulon 1; Dynatech, Chantilly, VA) were coated with $100 \mu \mathrm{L}$ of goat antimouse IgG (Jackson Immunoresearch Laboratories, West Grove, PA) diluted to $2 \mu \mathrm{g} / \mathrm{mL}$ in $0.1 M$ carbonate bicarbonate buffer $\mathrm{pH} 9.6$ for $1.5 \mathrm{~h}$ at $39^{\circ} \mathrm{C}$. After each incubation, the 
Table 2. Severity estimation scheme, based on systemic disease signs, for the classification of heifers following an experimental inoculation with Escherichia coli P4:O32 (Vangroenweghe et al., 2004a). Briefly, the 4 parameters are scored, total score is calculated, and compared with respective ranges for classification into mild, moderate, or severe disease.

\begin{tabular}{lll}
\hline Variable & Criteria & Score \\
\hline Rectal temperature $\left({ }^{\circ} \mathrm{C}\right)$ & $37.80-39.25$ & 0 \\
& $39.30-39.80$ & 1 \\
Skin turgor & $<37.80$ or $>39.80$ & 2 \\
& Regains normal shape in $<5 \mathrm{~s}$ & 0 \\
Rumen motility rate & Regains normal shape in $>5 \mathrm{~s}$ & 1 \\
(contractions/min) & $3 \times$ per 2 min & 0 \\
& $1-2 \times$ per 2 min & 1 \\
General attitude & 0× per 2 min & 2 \\
(signs of depression) & Alert & 0 \\
& Lethargic & 1 \\
Total score & Depressed: unable to stand & 2 \\
& Extremely sick: recumbent & 3 \\
& Mild disease & $0-2$ \\
& Moderate disease & $3-5$ \\
& Severe disease & $6-8$ \\
\hline
\end{tabular}

plates were washed 5 times with PBS supplemented with $0.1 \%$ (vol/vol) Tween 20 . Unsaturated binding sites were blocked with a solution of $0.5 \%$ (wt/vol) gelatin. The sequence of incubation steps with $100 \mu \mathrm{L}$ reagents diluted with PBS-Tween plus $0.1 \%$ gelatin was as follows: (i) a 1/10,000 dilution of the anti-C5a mouse monoclonal antibody $6 \mathrm{G} 4$ for $1 \mathrm{~h}$; (ii) 2-fold dilutions of purified $\mathrm{C} 5 \mathrm{a}^{\mathrm{des} A r g}$ for the calibration curve, or appropriate dilutions of the milk whey sample under test, diluted in PBS-Tween plus $0.1 \%$ gelatin containing $1 \mathrm{mM}$ EDTA for $1.5 \mathrm{~h}$; (iii) a 1/5000 dilution of rabbit antibovine C5a/C5 for $30 \mathrm{~min}$; (iv) a 1/10,000 dilution of horseradish peroxidase-conjugated goat antirabbit IgG (Jackson Immunoresearch Laboratories) for $30 \mathrm{~min}$; (v) $52 \mathrm{mM}$ 2,2'-azido-di-(3-ethylbenzthiazoline-6-sulfonic acid) (Sigma) in $0.1 M$ citrate buffer $\mathrm{pH} 4.2$ with 7.5 $\mathrm{m} M$ hydrogen peroxide (Sigma). The absorbance at 415 $\mathrm{nm}$ was read after $30 \mathrm{~min}$ using an automated microplate reader (BioKinetics Reader; BioTek Instruments). Values expressed in picograms per milliliter were extrapolated using linear regression from a standard curve of known amounts of C5 $\mathrm{a}^{\text {desArg }}$ (Rainard et al., 1998).

\section{Determination of sCD14}

A sandwich ELISA was used to quantify sCD14 levels in milk whey as described by Bannerman et al. (2003). Briefly, flat-bottom 96-well plates were coated overnight with $5 \mu \mathrm{g} / \mathrm{mL}$ of mouse antibovine CD14 monoclonal antibody (CAM36A; VMRD, Inc., Pullman, WA) diluted in $0.05 M$ sodium carbonate-bicarbonate (Sigma), pH 9.6 at $4{ }^{\circ} \mathrm{C}$. The plates were washed 4 times with $0.05 \%$ Tween 20 diluted in $50 \mathrm{~m} M$ Trizma-buffered saline (Sigma), $\mathrm{pH} 8.0$, and subsequently blocked with $2 \%$ fish skin gelatin (Sigma) for $1 \mathrm{~h}$ at room temperature. Plates were washed and $100 \mu \mathrm{L}$ of diluted whey samples (1:10) were added to each well in duplicate. Plates were incubated for $1 \mathrm{~h}$ at room temperature and subsequently washed as above. Mouse antibovine CD14 antibody (MM61A clone; VMRD, Inc.) was conjugated to horseradish peroxidase using a commercially available kit (EZ-Link Plus Activated Peroxidase kit; Pierce Chemical Co., Rockford, IL) and used as the detection antibody. This horseradish peroxidase-conjugated antibovine CD14 antibody was diluted 1:1000 in Trizmabuffered saline wash buffer containing $2 \%$ gelatin, and $100 \mu \mathrm{L}$ of the resulting solution was added to each well. Plates were incubated for $1 \mathrm{~h}$ at room temperature, washed as above, and $100 \mu \mathrm{L}$ of TMB substrate solution (Pierce Chemical Co.) added to each well. The reaction was stopped by the addition of $100 \mu \mathrm{L}$ of $2 M \mathrm{H}_{2} \mathrm{SO}_{4}$ and the absorbance read at $450 \mathrm{~nm}$ on a microplate reader (Multiskan PLUS; Labsystems, Helsinki, Finland). A background correction reading of $550 \mathrm{~nm}$ was subtracted from the 450-nm absorbance readings. Values expressed in micrograms per milliliter were extrapolated using linear regression from a standard curve of known amounts of recombinant bovine sCD14 (Wang et al., 2002).

\section{Determination of LBP}

Milk whey and plasma LBP levels were determined with a commercially available LBP ELISA kit that cross-reacts with bovine LBP (Cell Sciences, Inc., Norwood, MA). Milk and plasma samples were diluted 1:400 and 1:1500, respectively, and assayed according 
to the manufacturer's instructions. Briefly, diluted milk whey or plasma samples were added to flat-bottomed microtiter plates, precoated with solid bound antibodies recognizing LBP of a wide variety of species, and incubated at room temperature for $1 \mathrm{~h}$. The plates were washed 3 times and biotinylated LPS-tracer molecules were added. Following incubation $\left(1 \mathrm{~h}, 20^{\circ} \mathrm{C}\right)$ and 3 washings, streptavidin-peroxidase conjugated LBP was added $\left(1 \mathrm{~h}, 20^{\circ} \mathrm{C}\right)$. After washing the nonbound conjugated LBP, freshly prepared substrate solution (TMB) was added and the plates were incubated for $30 \mathrm{~min}$ $\left(20^{\circ} \mathrm{C}\right)$. The enzymatic reaction was stopped by addition of citric acid. The optical density at $450 \mathrm{~nm}$ and a correction wavelength of $550 \mathrm{~nm}$ were measured on a microplate reader (Multiskan PLUS; Labsystems). The concentration of LBP (expressed in $\mu \mathrm{g} / \mathrm{mL}$ ) was calculated by extrapolation using linear regression from a standard curve of known amounts of human LBP.

\section{Determination of $\mathrm{PGE}_{2}$}

Milk whey and plasma $\mathrm{PGE}_{2}$ concentrations were determined with a commercially available $\mathrm{PGE}_{2}$ competitive ELISA kit (Neogen, Lexington, KY) according to manufacturer's instructions. Briefly, quarter milk samples were filtered using a 70- $\mu \mathrm{m}$ cell strainer (Becton Dickinson; Erembodegem, Belgium) to discard cell clusters. One milliliter of milk or plasma sample was diluted with $1 \mathrm{~mL}$ of distilled water, and $1 \mathrm{~mL}$ of the mixture was loaded on a 100-mg C18 column (Varian, St.-Katelijne-Waver, Belgium) after conditioning with $2 \mathrm{~mL}$ of methanol followed by $2 \mathrm{~mL}$ of distilled water. The column was subsequently washed with $1 \mathrm{~mL}$ of each of the following substances: distilled water, methanol:distilled water (30:70), and hexane. The column was centrifuged at $3200 \times g$ for 3 min to remove any trace of hexane. Finally, eicosanoids were eluted from the C18 column with $1 \mathrm{~mL}$ of methanol. The collected eluate was evaporated to dryness under a stream of nitrogen. Dried samples were reconstituted in an appropriate volume of assay buffer.

Fifty microliters of the sample was added to the flatbottomed microtiter plates, precoated with mouse monoclonal antibodies against $\mathrm{PGE}_{2}$. Subsequently, 50 $\mu \mathrm{L}$ of diluted enzyme conjugate was added and the mixture was incubated at $20^{\circ} \mathrm{C}$ for $1 \mathrm{~h}$. After the plates were washed, $150 \mu \mathrm{L}$ of substrate solution (TMB) was added and incubated $\left(15 \mathrm{~min}, 20^{\circ} \mathrm{C}\right.$ ). The optical density at $630 \mathrm{~nm}$ and a correction wavelength at $490 \mathrm{~nm}$ were measured on a microplate reader (Multiskan PLUS; Labsystems). The concentration of $\mathrm{PGE}_{2}$ (expressed in $\mathrm{pg} / \mathrm{mL}$ ) was calculated by extrapolation using linear regression from a standard curve of known amounts of $\mathrm{PGE}_{2}$.

\section{Determination of Thromboxane $B_{2}$}

Milk and plasma thromboxane $\mathrm{B}_{2}\left(\mathbf{T X B}_{2}\right)$ concentrations were determined with a commercially available $\mathrm{TXB}_{2}$ competitive ELISA kit (Neogen, Lexington, KY) according to manufacturer's instructions. Samples were prepared for analysis as described above for $\mathrm{PGE}_{2}$. Briefly, $50 \mu \mathrm{L}$ of the sample was added to the flatbottomed microtiter plates, and precoated with rabbit monoclonal antibodies against $\mathrm{TXB}_{2}$. After addition of $50 \mu \mathrm{L}$ of diluted enzyme conjugate, the mixture was incubated at $20^{\circ} \mathrm{C}$ for $1 \mathrm{~h}$. Following washing, $150 \mu \mathrm{L}$ of substrate (TMB) was added $\left(15 \mathrm{~min}, 20^{\circ} \mathrm{C}\right)$. The optical density at $630 \mathrm{~nm}$ and a correction wavelength at 490 nm were measured on a microplate reader (Multiskan PLUS; Labsystems). The concentration of $\mathrm{TXB}_{2}$ (expressed in $\mathrm{pg} / \mathrm{mL}$ ) was calculated by extrapolation using linear regression from a standard curve of known amounts of $\mathrm{TXB}_{2}$.

\section{Statistical Analyses}

To compare the 2 treatment groups with respect to the various parameters analyzed in blood and milk, a mixed model was used with cow as random effect, and treatment, time, and their interaction as categorical fixed effects. Furthermore, the 2 treatment groups were compared at PIH 12 for all analyzed parameters, and some determined parameters were tested at posttreatment intervals PIH 12 to 18 (RT, HR, blood leukocyte number, and packed cell volume), PIH 12 to 48 (IL-8, C5a, sCD14, LBP, $\mathrm{PGE}_{2}$, and $\mathrm{TXB}_{2}$ ) and PIH 12 to 72 ( $\mathrm{SCC}$, cfu, lactose, $\mathrm{Na}^{+}, \mathrm{K}^{+}, \mathrm{Cl}^{-}$, and serum albumin), respectively, for significant differences between both treatment groups. Bonferroni's multiple comparisons procedure with an overall type I error equal to $5 \%$ was used to adjust for multiple comparisons. Quarter milk production in both infected and uninfected quarters was tested for significant differences between treatments at $d+1$ and the interval $d+1-d+3$. The effect of treatment on the local aspects of the mammary gland and the clinical severity score was tested by the Wilcoxon rank sum test.

\section{RESULTS}

\section{Local and Systemic Inflammatory Response}

Following intramammary E. coli inoculation, RT rapidly increased from PIH 9 onward, to reach a maximum at PIH 12 in the saline-treated group. Carprofen administration at PIH 9 immediately reduced $\mathrm{RT}(P<0.0001)$ at 3 (PIH 12) and $6 \mathrm{~h}$ (PIH 15) posttreatment, and RT normalized at PIH 15 ( $6 \mathrm{~h}$ posttreatment). No relapses of $\mathrm{RT}$ increase were observed in the carprofen-treated 
group, whereas in the saline-treated group, RT increased above $39^{\circ} \mathrm{C}$ again at PIH 24 (Figure 1a).

Heart rate followed almost identical kinetics as described for RT. In the carprofen-treated group, HR was $(P<0.05)$ lower at PIH 12 and 15 . From $6 \mathrm{~h}$ posttreatment onward, HR in the carprofen-treated animals remained lower, although not significant, until the end of the observation period (Figure 1b). Respiration rate followed identical kinetics as RT and HR (results not shown).

Carprofen treatment following intramammary E. coli inoculation has a beneficial effect on the duration of reticulorumen motility depression. Although reticulorumen motility was equally depressed in both treatment groups at PIH 9 (time of treatment), the depression disappeared following carprofen treatment $(P<$ 0.01 ), whereas in the saline-treated group, depression of reticulorumen motility reached its maximum at $\mathrm{PIH}$ 12 (Figure 1c).

Local clinical symptoms at the level of the mammary gland were also assessed during clinical examination. Local swelling appeared at PIH 6 and reached its maximum at PIH 12 in both treatment groups. In the carprofen-treated animals, quarter swelling decreased from PIH 18 and normal quarter consistency was present at PIH 144. Quarter swelling decreased more slowly in control animals, although normal quarter consistency at palpation was also reached by $\mathrm{PIH} 144$. Maximal quarter swelling score was lower $(P<0.05)$ in the carprofen-treated animals. Milk appearance, quarter milk leakage scores, and maximum milk leakage scores were significantly $(P<0.05)$ higher in the carprofen-treated group at PIH 12. Quarter pain and temperature did not differ between the treatment groups (results not shown).

\section{Clinical Severity Scoring}

Based on the clinical severity scoring system by Vangroenweghe et al. (2004a), clinical scores increased to a maximum in both treatment groups at PIH 12. The clinical severity score in the carprofen-treated group decreased more rapidly from $6 \mathrm{~h}$ posttreatment onwards. At PIH 15, clinical severity score was lower $(P$ $<0.01$ ) in the carprofen-treated group compared with the saline-treated group.

At PIH 9, the time of treatment, approximately equal numbers of animals in both treatment groups displayed a mild and moderate response. Following carprofen administration, all animals $(\mathrm{n}=12)$ responded mildly (score 0 to 2), whereas in the saline-treated group, 6 animals reacted with a moderate response (score 3 to 5), and only 7 animals had a mild response. By $6 \mathrm{~h}$ posttreatment, 10 animals in the carprofen-treated
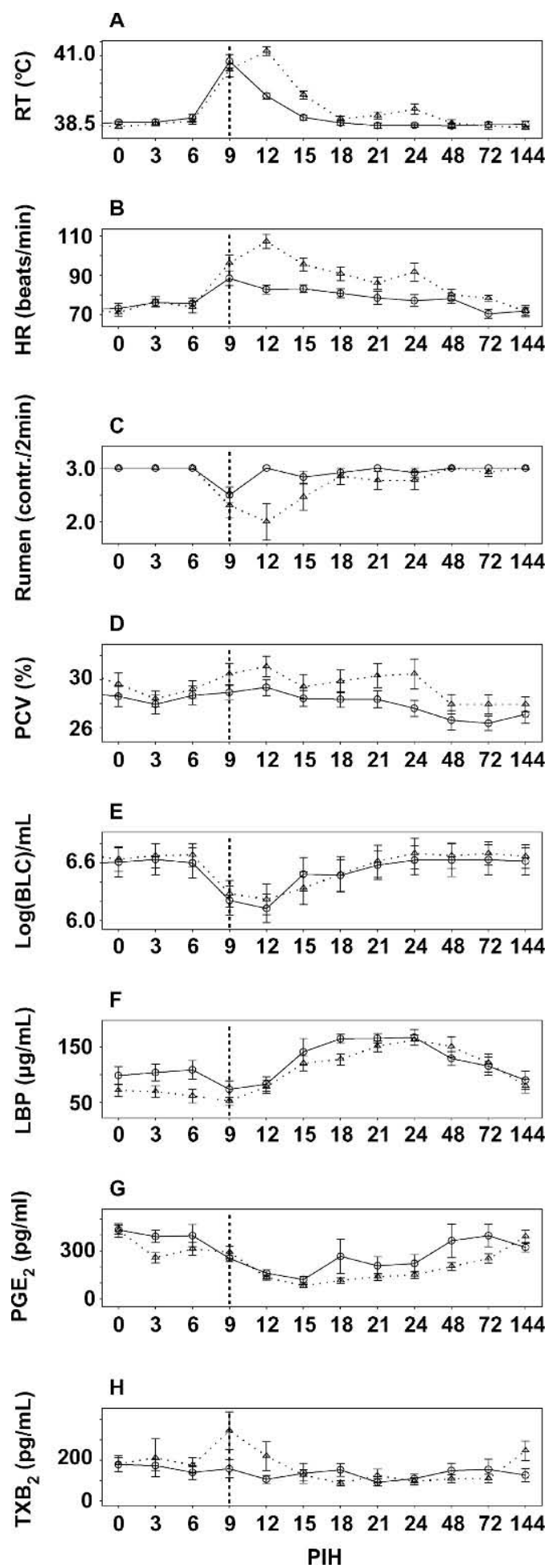

Figure 1. Rectal temperature $(\mathrm{RT})(\mathrm{A})$, heart rate $(\mathrm{HR})(\mathrm{B})$, reticulorumen motility (contractions per $2 \mathrm{~min})(\mathrm{C})$, packed cell volume (D), blood leukocyte count (BLC) (E), plasma LPS-binding protein (LBP) (F), plasma prostaglandin $\mathrm{E}_{2}(\mathrm{G})$, and plasma thromboxane $\mathrm{B}_{2}\left(\mathrm{TXB}_{2}\right)(\mathrm{H})$ from postinfusion hour (PIH) 0 until PIH 144 from primiparous cows infused with $1 \times 10^{4} \mathrm{cfu}$ of Escherichia coli P4:O32 and treated at PIH 9 (vertical dashed line) with carprofen (solid line; $n=12$ ) or saline (dotted line; $n=13)$. Data are means $( \pm$ SEM). 
Table 3. Classification of heifers into mild/moderate/severe responders based on the severity estimation score at postinfusion hour (PIH) 9, 12, and 15. The numbers in the body of the table represent the number of animals having the specified score at the respective PIH. In the present study, the total score did not exceed 5, meaning that no severe responses were observed throughout the entire experimental study period.

\begin{tabular}{|c|c|c|c|c|c|c|c|c|c|c|}
\hline \multirow[b]{3}{*}{$\mathrm{PIH}$} & \multirow[b]{3}{*}{ Group } & \multicolumn{9}{|c|}{ Clinical score } \\
\hline & & \multicolumn{3}{|c|}{ Mild response } & \multicolumn{3}{|c|}{ Moderate response } & \multicolumn{3}{|c|}{ Severe response } \\
\hline & & 0 & 1 & 2 & 3 & 4 & 5 & 6 & 7 & 8 \\
\hline \multirow[t]{2}{*}{9} & Saline & 2 & 1 & 4 & 6 & 0 & 0 & 0 & 0 & 0 \\
\hline & Carprofen & 0 & 0 & 7 & 5 & 0 & 0 & 0 & 0 & 0 \\
\hline \multirow[t]{2}{*}{12} & Saline & 0 & 0 & 7 & 4 & 2 & 0 & 0 & 0 & 0 \\
\hline & Carprofen & 2 & 6 & 4 & 0 & 0 & 0 & 0 & 0 & 0 \\
\hline \multirow[t]{2}{*}{15} & Saline & 3 & 4 & 5 & 1 & 0 & 0 & 0 & 0 & 0 \\
\hline & Carprofen & 10 & 1 & 0 & 1 & 0 & 0 & 0 & 0 & 0 \\
\hline
\end{tabular}

group had a score of 0 , whereas in the saline-treated group, only 3 animals had a score of 0 ; the others scored $1(\mathrm{n}=4), 2(\mathrm{n}=5)$, or $3(\mathrm{n}=1)$ (Table 3$)$. At the subsequent time points, the clinical severity score in both groups seemed to normalize with only a slight flare-up of 3 animals (score 2) in the saline-treated group at PIH 24.

\section{Quarter Milk Production}

Milk production in the infected quarters decreased equally on d 0 , the day of intramammary $E$. coli challenge, in both treatment groups. In this study, carprofen treatment did not significantly affect the recovery of milk production in the infected quarters compared with saline treatment (Figure 2a). In the uninfected control quarters, no significant differences in milk production were observed throughout the entire study period (Figure $2 b$ ).

As expected, none of the animals in either treatment group reacted as severe responder, based on the quarter milk production of the uninfected quarters at $d+2 \mathrm{com}$ pared with the quarter milk production in these quarters at $d-1$ (Vandeputte-Van Messom et al., 1993). This is in agreement with recent findings that primiparous cows react moderately following intramammary $E$. coli challenge (Vangroenweghe et al., 2004a,b).

\section{Intramammary Growth of Inoculated E. coli, SCC, Packed Cell Volume, and Blood Leukocyte Count}

The number of $E$. coli increased to plateau [4.07 and $3.89 \log _{10}(\mathrm{cfu}) / \mathrm{mL}$ at PIH 6. This plateau was followed by a slow, but steady decrease in both treatment groups. No significant differences in the number of $E$. coli (PIH 12 to 48) were observed throughout the experimental period (Figure 3a). Somatic cell count increased during the early phase of inflammation, although SCC only exceeded $1 \times 10^{6}$ cells $/ \mathrm{mL}$ at PIH 9 in both treatment groups. Following treatment at PIH 9, no significant differences in SCC (PIH 12 to 48) were observed throughout the experimental period (Figure $3 \mathrm{~b}$ ).

A decrease in blood leukocyte number occurred from PIH 9 onwards, and nadir blood leukocyte number was reached at PIH 12. This was followed by a steady increase to preinfection levels at PIH 24 (Figure 1e). Blood leukocyte count did not differ significantly between both treatment groups during the period immediately following intravenous carprofen treatment (PIH 12 to 18).

\section{Milk Composition}

Lactose, serum albumin, sodium, potassium, and chlorine are indicators of changes in milk composition following mastitis (Burvenich, 1983). Following $E$. coli challenge, lactose concentration started to decrease at PIH 9, reaching nadir at PIH 12 (3 h posttreatment) in both treatment groups. No significant differences (PIH 12 to 48) in lactose concentration were observed following carprofen treatment (Figure 3c). Maximal concentrations of serum albumin in milk were reached at PIH 15. In the interval PIH 12 to 48, serum albumin concentration showed an interaction between time and treatment $(P=0.013)$, meaning that serum albumin kinetics were different between groups. At PIH 21, carprofen-treated animals had lower concentrations of serum albumin in the milk of the affected quarters $(P=$ 0.0099; Figure 3d).

Concentration of $\mathrm{Na}^{+}$was lower in the carprofentreated animals at PIH $21(P=0.005)$ and PIH $24(P=$ 0.007), whereas the $\mathrm{K}^{+}$concentration was higher in the carprofen-treated animals at PIH $21(P=0.002)$ and PIH $24(P=0.005)$ (Figure 3e and f). The $\mathrm{Cl}^{-}$concentration was lower in the carprofen-treated group than the saline-treated group at PIH $21(P=0.013)$ (Figure $3 g)$.

\section{Milk IL-8, C5a, and SCD14}

Before challenge, IL-8 was very low (1.66 \pm 0.23 and $2.11 \pm 0.35 \mathrm{pg} / \mathrm{mL}$ in the saline and carprofen-treated 


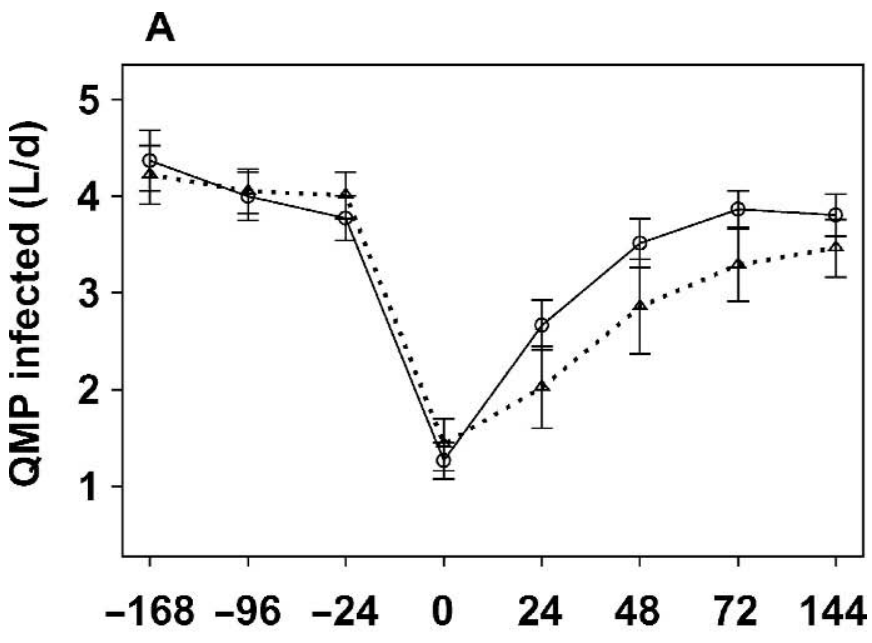

B

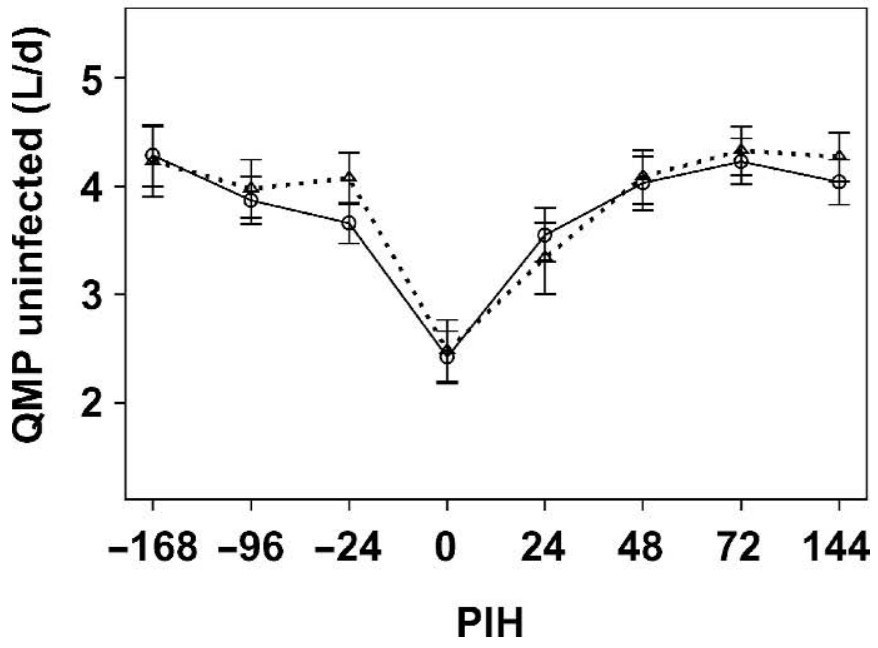

Figure 2. Quarter milk production (QMP) in the infected (A) and uninfected (B) quarters from PIH -168 until PIH 144 from primiparous cows infused with $1 \times 10^{4}$ cfu of Escherichia coli P4:O32 and treated at PIH 9 with carprofen (solid line; $\mathrm{n}=12$ ) or saline (dotted line; $\mathrm{n}=13)$. Data are means $( \pm \mathrm{SEM})$.

groups, respectively) in the quarters that were to be infused with $E$. coli. Until PIH 9 (the time of treatment), IL-8 kinetics did not differ between both treatment groups. Peak concentrations ( $471 \pm 50$ and $389 \pm 61 \mathrm{pg} /$ $\mathrm{mL}$ for the saline- and carprofen-treated group, respectively) were reached in the period PIH 12 to 15 . No significant differences between treatments could be observed throughout the study period (Figure 4a).

The complement component C5a had similar kinetics in both treatment groups until PIH 18, 9 h posttreatment. From PIH 21, C5a concentration decreased in the treated animals, whereas animals in the salinetreated groups reached peak C5a levels at PIH 24, fol-

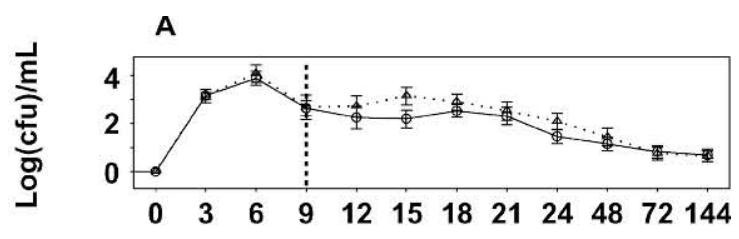

B
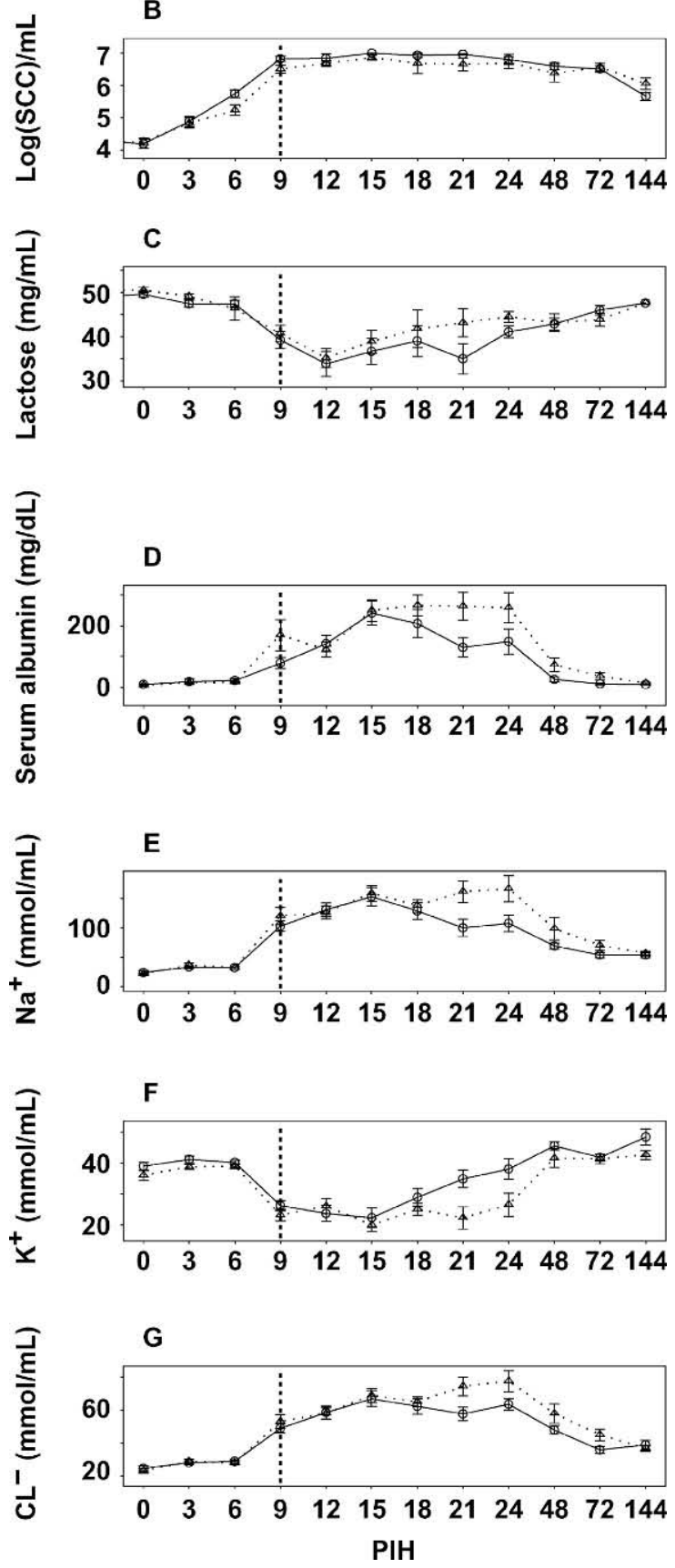

Figure 3. Colony-forming units of Escherichia coli (A), SCC (B), lactose (C), serum albumin (D), sodium (E), potassium (F), and chlorine $(\mathrm{G})$ in the infected quarters from postinfusion hour (PIH) 0 until PIH 144 from primiparous cows infused with $1 \times 10^{4} \mathrm{cfu}$ of $E$. coli P4:O32 and treated at PIH 9 (dashed vertical line) with carprofen (solid line; $\mathrm{n}=12$ ) or saline (dotted line; $\mathrm{n}=13$ ). Data are means $( \pm$ SEM) 

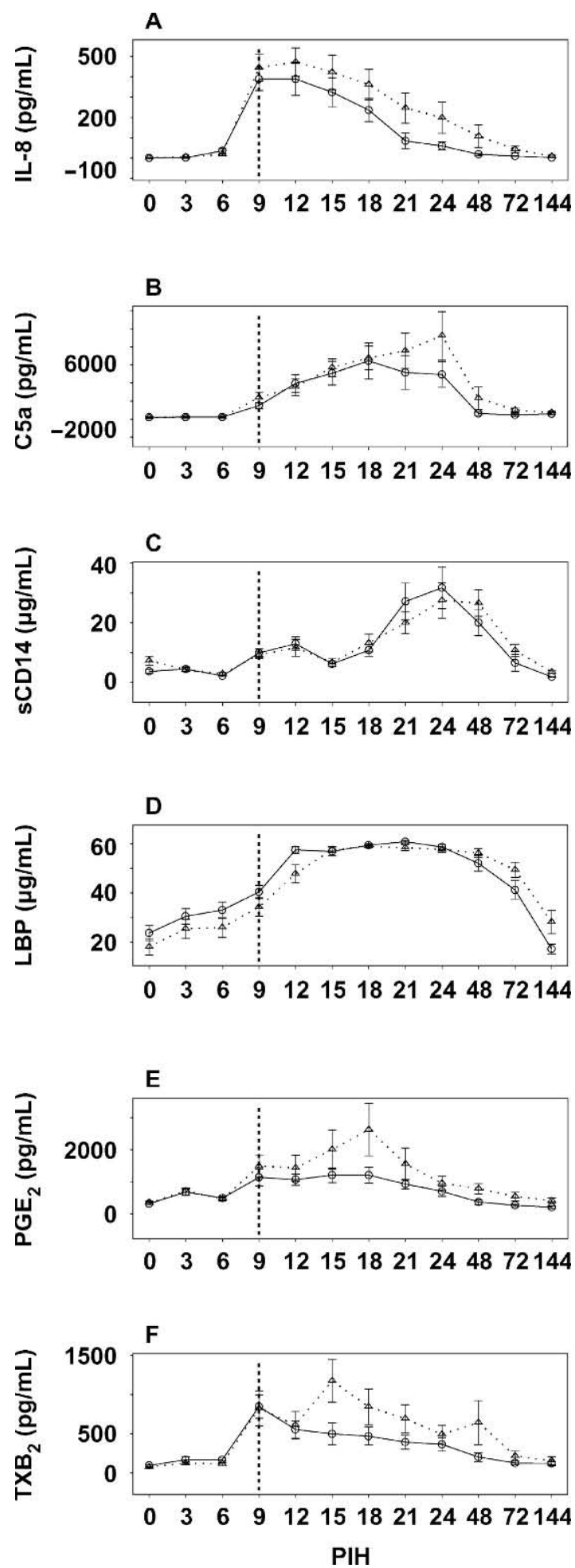

Figure 4. Concentrations of IL-8 (A), complement component 5a (B), soluble CD14 (C), LPS-binding protein (D), prostaglandin $\mathrm{E}_{2}(\mathrm{E})$, and thromboxane $\mathrm{B}_{2}(\mathrm{~F})$ in the infected quarters from postinfusion hour (PIH) 0 until PIH 144 from primiparous cows infused with $1 \times$ $10^{4}$ cfu of Escherichia coli P4:O32 and treated at PIH 9 (dashed vertical line) with carprofen (solid line; $\mathrm{n}=12$ ) or saline (dotted line; $\mathrm{n}=13)$. Data are means $( \pm \mathrm{SEM})$ lowed by a decrease at PIH 48, but no significant differences between the 2 groups were observed. At PIH 72, C5a levels in both groups reached similar values (Figure $4 \mathrm{~b})$.

Before challenge, sCD14 concentration in mammary quarters $(7.33 \pm 1.72$ and $3.77 \pm 0.70 \mu \mathrm{g} / \mathrm{mL}$ in salineand carprofen-treated animals, respectively) was in a range similar to that reported by Lee et al. (2003a) for early lactating uninfected glands (5.46 to $6.90 \mu \mathrm{g} / \mathrm{mL}$ ). In both treatment groups, a first peak was observed at PIH 12 (11 \pm 2 and $13 \pm 2 \mu \mathrm{g} / \mathrm{mL}$, respectively) followed by a second, higher peak at PIH $24(27 \pm 4$ and $31 \pm 6 \mu \mathrm{g} /$ $\mathrm{mL})$. Following peak concentrations, sCD14 decreased from $\mathrm{PIH} 48$ to reach normal preinfection values by $\mathrm{PIH}$ 144. No significant differences in $\mathrm{sCD} 14$ concentrations were observed throughout the entire experimental period (Figure 4c).

\section{Plasma and Milk LBP}

It was shown previously (Bannerman et al., 2003) that elevated levels of sCD14 were associated with similar increases in milk LBP, thereby providing an environment for optimal host recognition of LPS, originating from inoculated $E$. coli bacteria. In addition to quantifying milk LBP to assess possible effects of carprofen treatment on the levels of LBP in the infected quarters, plasma LBP was assayed, as it is known that hepatic synthesis of this protein increases during the acutephase response, mainly due to hepatic cell stimulation by IL-1 $\beta$ and IL-6 (Tobias et al., 1999), which could be influenced by NSAID treatment through the intermediate eicosanoid products, $\mathrm{PGE}_{2}$ and $\mathrm{TXB}_{2}$. Under basal conditions, LBP was detected in bovine blood at concentrations of $71.3 \pm 10.9$ and $98.3 \pm 16.2 \mu \mathrm{g} / \mathrm{mL}$ for salineand carprofen-treated animals, respectively; whereas the concentration of LBP in milk was lower, at $18.1 \pm$ 2.3 and $23.7 \pm 2.2 \mu \mathrm{g} / \mathrm{mL}$ for the 2 groups, respectively. Plasma LBP increased from PIH 15 onwards to reach maximal values at PIH $24(162 \pm 10$ and $167 \pm 14 \mu \mathrm{g} / \mathrm{mL}$ for saline- and carprofen-treated animals, respectively). Thereafter, concentrations of plasma LBP declined to reach preinfection levels at PIH 144 (Figure 1f). In quarters inoculated with $E$. coli, milk LBP was elevated from PIH 9 onwards, with maxima (58 \pm 1 and $61 \pm 1$ $\mu \mathrm{g} / \mathrm{mL}$ in saline- and carprofen-treated animals, respectively) at PIH 21. From PIH 48 on, milk LBP concentrations declined (Figure 4d). Milk LBP was significantly lower in the carprofen-treated than saline-treated animals at PIH $12(P=0.0001)$.

\section{Plasma and Milk $\mathrm{PGE}_{2}$ and $\mathrm{TXB}_{2}$}

Plasma $\mathrm{PGE}_{2}$ concentration was $429.2 \pm 25.2 \mathrm{pg} / \mathrm{mL}$ at the time of inoculation in both treatment groups. 
Prostaglandin $\mathrm{E}_{2}$ started to decrease in plasma as early as PIH 9 and reached nadir at PIH 15 in both treatment groups. Plasma $\mathrm{PGE}_{2}$ concentrations did not differ significantly between carprofen-treated and saline-treated animals (Figure 1g). Thromboxane $\mathrm{B}_{2}$ concentration in plasma was as high as $180.4 \pm 26.5 \mathrm{pg} / \mathrm{mL}$ at the time of infection. Throughout the inflammatory episode, no significant difference between $\mathrm{TXB}_{2}$ kinetics in the treatment groups was observed (Figure $1 \mathrm{~h}$ ).

In milk, $\mathrm{PGE}_{2}$ concentration was lower than in plasma and was $334.8 \pm 21.1 \mathrm{pg} / \mathrm{mL}$ at the time of intramammary inoculation. Prostaglandin $\mathrm{E}_{2}$ subsequently increased from PIH 9 onward in both treatment groups. No significant difference in milk $\mathrm{PGE}_{2}$ concentration was observed between the carprofen- and the saline-treated animals (Figure 4e). Initial milk $\mathrm{TXB}_{2}$ concentrations $(84.3 \pm 5.1 \mathrm{pg} / \mathrm{mL})$ were markedly lower than concentrations observed in plasma. Thromboxane $\mathrm{B}_{2}$ increases occurred at PIH 9, which was also the maximal concentration, in the carprofen-treated animals. In saline-treated animals, $\mathrm{TXB}_{2}$ further increased and reached its maximum at PIH 15. The milk $\mathrm{TXB}_{2}$ concentrations continued to be higher in the salinetreated groups compared with the carprofen-treated animals until PIH 72, but the difference was not significant.

\section{DISCUSSION}

The aim of the present study was to evaluate the potential modulatory effects of carprofen treatment on a moderate inflammatory reaction following $E$. coli challenge. Carprofen is a PG synthetase inhibitor via COX inhibition. Therefore, the study design included carprofen administration following the appearance of initial clinical symptoms (Shpigel et al., 1994) and inflammatory dynamics of the moderate inflammatory model used (Vangroenweghe et al., 2004a,b). It is known that pretreatment is more effective in inhibiting the inducible COX-2 enzyme (Burvenich, 1985; Burvenich et al., 1989); however, from a practical point of view, the earliest occasion at which field cases of clinical $E$. coli mastitis can be diagnosed and subsequently treated, occurs at the milking following the infection of the mammary quarter (Shpigel et al., 1994, 1996). The first clinical signs ( $\mathrm{RT}>40^{\circ} \mathrm{C}$, quarter swelling, slightly abnormal milk appearance) in the present experimental model, using a $1 \times 10^{4} \mathrm{cfu}$ inoculum dose, appeared around PIH 9. Therefore, the choice for a carprofen administration at PIH 9 was considered most suitable, as clinical signs $\left(\mathrm{RT}=40.6 \pm 0.17^{\circ} \mathrm{C}\right.$ ) would be present at that time, although maximal $\mathrm{RT}$ was not yet reached (Vangroenweghe et al., 2004a,b).
In the present study, the same strain and high inoculum dose of $E$. coli was used to induce a moderate inflammatory reaction in primiparous cows as described previously (Vangroenweghe et al., 2004a,b). The clinical course and changes in different laboratory parameters following intramammary $E$. coli challenge in the control animals were similar to animals receiving the same dose $\left(1 \times 10^{4} \mathrm{cfu}\right)$ in previous experiments (Vangroenweghe et al., 2004a,b). Carprofen-treated animals demonstrated an immediate and significant decrease in RT at $3 \mathrm{~h}$ posttreatment, whereas pyrexia continued in the control animals with a peak fever at PIH 12. Singledose carprofen administration in the present study resulted in a more pronounced and prolonged antipyretic effect compared with meloxicam treatment in an $E$. coli endotoxin model (Banting et al., 2000), where peak fever was reached at $2 \mathrm{~h}$ posttreatment in both groups. Reticulorumen motility was equally depressed in both treatment groups at the time of carprofen administration. However, $3 \mathrm{~h}$ posttreatment, reticulorumen motility in the carprofen-treated animals returned to normal, whereas a maximal depression was reached in the control group at PIH 12. A similar effect on reticulorumen motility was observed with meloxicam treatment in the $E$. coli endotoxin model (Banting et al., 2000).

Improvement of local clinical signs at the level of the affected mammary quarters by carprofen treatment was limited to swelling and milk appearance. These observations are in accordance with Anderson et al. (1986), who reported significant improvement of quarter temperature, edema, pain, and size following flunixin meglumine treatment of cows suffering from endotoxin-induced mastitis. However, the administration of flunixin meglumine in that study was performed much earlier (PIH 2) than in our study, where carprofen was only administered at appearance of the first clinical symptoms, such as an elevated $\mathrm{RT}\left(>40^{\circ} \mathrm{C}\right)$, quarter swelling, and slightly abnormal milk appearance.

Dehydration is often assessed during acute coliform mastitis as an easy tool to judge clinical severity. The assessment of dehydration can be performed by skin turgor estimation. In the present study, no difference in skin turgor could be observed throughout the study period. This could have been expected based on the mild to moderate responses usually obtained using this experimental infection model. Packed cell volume did not differ among treatments throughout the study either.

Clinical scores, combining several clinical parameters, have been described (Wenz et al., 2001; Friton et al., 2002; Vangroenweghe et al., 2004a). Using the clinical severity score described by Vangroenweghe et al. (2004a), carprofen-treated animals had a significantly lower clinical score at PIH 12 and 15 compared 
with the saline-treated group (Table 3). Although, as expected from previous trials, all animals in both groups responded mildly to moderately following $E$. coli challenge, the carprofen-treated animals generally showed a lower clinical severity score within $3 \mathrm{~h}$ of NSAID administration. This was mainly due to the restoration of reticulorumen motility and antipyretic activity of the NSAID.

Quarter inflammation was associated with a temporary loss of milk production, combined with secretion of abnormal milk from the infected glands. Maximal depression in milk production in the infected and uninfected quarters occurred on the day of challenge (d 0), and was followed by a rapid recovery during subsequent days. Carprofen treatment exerted no significant beneficial effect on milk yield in the infected quarters following intramammary $E$. coli challenge. The absence of any significant effect of carprofen on the milk production in the uninfected right quarters may be attributed to the moderate inflammatory signs of the present mastitis model.

In the present study, no significant effect of carprofen treatment on bacterial elimination occurred, which could be expected as carprofen treatment was administered alone and not as an adjunctive therapy to intramammary or systemic antibiotics. Fluoroquinolones are known to enhance bacterial clearance during experimentally induced $E$. coli mastitis (Monfardini et al., 1999). Rantala et al. (2002) reported a more rapid decline in bacterial number in the infected quarters following combined flunixin meglumine and fluoroquinolone treatment, which could probably be attributed to the fluoroquinolone treatment and not the adjunctive NSAID therapy.

The leukocyte influx into the infected glands following $E$. coli challenge was not significantly affected by carprofen treatment. This could assure continuing elevated levels of PMNL at the site of infection, facilitating their local role in combating $E$. coli bacteria present in the infected glands. This observation is in accordance with previous results obtained using flurbiprofen in experimentally induced LPS mastitis in goats (Burvenich, 1985; Burvenich et al., 1989). Comparable results were obtained following ibuprofen treatment at $2 \mathrm{~h}$ postinfusion of endotoxin (DeGraves and Anderson, 1993). Although the dose of carprofen ( $1.4 \mathrm{mg} / \mathrm{kg}$ of BW) administered intravenously in the present study was twice as high as the dose $(0.7 \mathrm{mg} / \mathrm{kg}$ of BW) used by Lohuis et al. (1991), edema and leukocyte infiltration in the affected glands could not be prevented. Nevertheless, the applied treatment was potent enough to reduce eicosanoid generation in the affected mammary glands in the carprofen-treated animals. In the blood, similar kinetics could be observed in blood leukocyte number be- tween both treatment groups. Nadir blood leukocyte number was reached at PIH $12,3 \mathrm{~h}$ posttreatment in both treatment groups, and was followed by progressive recovery of blood leukocyte number to preinfection levels by PIH 24.

Lactose, serum albumin, sodium, potassium, and chlorine concentrations in milk of the infected quarters are often determined to assess the severity and duration of the intramammary inflammation. Serum albumin and all ions $\left(\mathrm{Na}^{+}, \mathrm{K}^{+}\right.$, and $\left.\mathrm{Cl}^{-}\right)$showed similar kinetics, with a significant interaction between time and treatment (not significant for $\mathrm{Cl}^{-}$) from $12 \mathrm{~h}$ posttreatment (PIH 21) onward in the carprofen-treated animals. These results indicate that carprofen induces a more rapid recovery of normal milk composition in animals intramammarily challenged with $E$. coli. Previous studies using ibuprofen in an endotoxin model were unable to demonstrate any effect on milk composition (DeGraves and Anderson, 1993). The terminal half-life of carprofen in healthy cows has been calculated to be 30.7 $\mathrm{h}$, which is shorter than the half-life of phenylbutazone (31.2 to $82.1 \mathrm{~h}$ ), but considerably longer than flunixin meglumine (8.1 h) (Lohuis et al., 1991). Therefore, it is not surprising that a single dose of carprofen had prolonged beneficial effects on clinical parameters compared with the control group.

Following intramammary $E$. coli challenge, significant increases in $\mathrm{PGE}_{2}$ (Zia et al., 1987; Peter et al., 1990) and $\mathrm{TXB}_{2}$ (Anderson et al., 1985, 1986; Zia et al., 1987) have been observed in milk. Moreover, a significant effect of flunixin meglumine administration on $\mathrm{TXB}_{2}$ concentrations was reported (Anderson et al., 1986). Even in the uninfected quarters, a slight increase in $\mathrm{PGF}_{2 \alpha}$ and $\mathrm{TXB}_{2}$ concentration was reported (Anderson et al., 1985), although this increase disappeared more rapidly than in the infected quarters. Following flunixin meglumine treatment, $\mathrm{TXB}_{2}$ concentrations remained at baseline levels, whereas in the saline-treated animals, a pronounced peak value was observed at PIH 8 in the endotoxin-challenged animals (Anderson et al., 1986). Similar trends were observed in the present study, but did not reach significance.

Although the effect of NSAID on eicosanoid production following inflammation is well documented in the literature (Anderson et al., 1986), no reports are available on the possible effect on other immunological inflammatory parameters, such as the chemotactic agents IL-8 and C5a or the early innate immune molecules sCD14 and LBP. Interleukin-8 kinetics in the present study were similar with previous reports using the same inoculum dose (Vangroenweghe et al., 2004b). Local IL-8 production started at PIH 6, although major increases only occurred from PIH 9 onwards. Because IL-8 is a well-known chemotactic agent, it is obvious 
from these results that the initial leukocyte influx into the infected quarters, which occurred around PIH 9, was not affected by the decline of IL- 8 occurring much later during inflammation. The appearance and evolution of C5a concentrations in the affected quarters did not differ between both groups until PIH 21 (12 h posttreatment). In the control group, C5a increased until maximal values at PIH 24, which is $6 \mathrm{~h}$ later than previously observed (Vangroenweghe et al., 2004b). The marked difference in the onset of carprofen effects on chemotactic agents IL-8 and C5a could be explained by the location of mediator production. Interleukin- 8 is directly produced by the epithelial cells in the mammary gland (Baggiolini and Clark-Lewis, 1992; Barber and Yang, 1998), whereas the bulk of C5a precursors are obtained from the blood through leakage of the disintegrated blood-milk barrier (Rainard et al., 1998; Rainard, 2003).

In accordance with previous reports (Bannerman et al., 2003; Vangroenweghe et al., 2004b), the increases in milk LBP paralleled increments in sCD14 levels. From a host perspective, the simultaneous increase in both LBP and sCD14 levels would be expected to be advantageous as both molecules act in concert to facilitate activation of host defense mechanisms by presenting LPS, released during bacterial growth and death, to the transmembrane LPS receptor, TLR-4 (Bannerman and Goldblum, 2003). Carprofen treatment did not significantly affect either parameter.

The present study showed that carprofen treatment following experimental $E$. coli challenge in a moderate inflammation model with primiparous cows has small modulatory effects on some of the inflammatory markers, but obvious effects on some of the key clinical markers, such as RT and reticulorumen motility. Administration of carprofen at PIH 9, when first clinical signs occurred, showed beneficial effects on general clinical condition, recovery of milk composition, and reduced production of eicosanoids. Mediators of early innate immune response, IL-8, C5a, sC14 and LBP, were not significantly affected by NSAID treatment.

\section{CONCLUSIONS}

The inflammatory model using primiparous cows during the periparturient period is a moderate state of inflammation, necessary to eliminate the invading pathogens from the affected mammary quarters. Carprofen treatment was administered late during the acute-phase reaction, when first clinical signs appeared, and had modulatory effects on clinical and immunological parameters. The main modulatory potential occurred at the level of improved clinical condition, mainly due to the antipyretic effects and the ability of carprofen to improve reticulorumen motility. Milk composition was significantly affected by carprofen treatment at PIH 21 and 24, but no further effects on milk composition occurred and milk production was not significantly affected. Carprofen treatment did not significantly affect $\mathrm{PGE}_{2}$ and $\mathrm{TXB}_{2}$ in plasma but reduced their concentrations in milk. Moreover, carprofen treatment did not result in a significant decrease of chemotactic inflammatory mediators, IL-8 and C5a, and early innate immune molecules, such as sCD14 and LBP. Major immunomodulatory effects from NSAID administration were therefore not observed in this model, although a larger study might confirm some apparent trends in the results presently obtained.

\section{ACKNOWLEDGMENTS}

The authors greatly acknowledge the excellent technical assistance of E. Vander Elstraeten, A. Vervloet, K. Demeyere, J. Vangroenweghe, G. Corneillie, E. Van Driessche, and A. Vangroenweghe. This study was sponsored by Ghent University (Belgium), FWO-Vlaanderen (No. 31520804) and Pfizer Animal Health (Sandwich, UK). We acknowledge C. McLaughlin and M. Stegemann for their scientific advice during the experiment and the critical review of the manuscript.

\section{REFERENCES}

Anderson, K. L. 1989. Therapy for acute coliform mastitis. Comp. Contin. Educ. Pract. Vet. 11:1125-1133.

Anderson, K. L., H. Kindahl, A. Petroni, A. R. Smith, and B. K. Gustafsson. 1985. Arachidonic acid metabolites in milk of cows during acute coliform mastitis. Am. J. Vet. Res. 46:1573-1577.

Anderson, K. L., H. Kindahl, A. R. Smith, L. E. Davis, and B. K. Gustafsson. 1986. Endotoxin-induced bovine mastitis: Arachidonic acid metabolites in milk and plasma and effects of flunixin meglumine. Am. J. Vet. Res. 47:1373-1377.

Baggiolini, M., and I. Clark-Lewis. 1992. Interleukin-8, a chemotactic and inflammatory cytokine. FEBS Lett. 307:97-101.

Bannerman, D. D., and S. E. Goldblum. 2003. Mechanisms of bacterial lipopolysaccharide-induced endothelial apoptosis. Am. J. Physiol. Lung Cell. Mol. Physiol. 284:L899-L914.

Bannerman, D. D., M. J. Paape, W. R. Hare, and E. J. Sohn. 2003. Increased levels of LPS-binding protein in bovine blood and milk following bacterial lipopolysaccharide challenge. J. Dairy Sci. 86:3128-3137.

Banting, A., H. Schmidt, and S. Banting. 2000. Efficacy of meloxicam in lactating cows with $E$. coli endotoxin induced acute mastitis. Abstract no. E4 in Proc. 8th Int. Congr. EAVPT, Jerusalem, Israel.

Barber, M. R., and T. J. Yang. 1998. Chemotactic activities in nonmastitic and mastitic mammary secretions: Presence of interleukin8 in mastitis but not in non-mastitic secretions. Clin. Diagn. Lab. Immunol. 5:82-86.

Brideau, C., C. Van Staden, and C. C. Chan. 2001. In vitro effects of cyclooxygenase inhibitors in whole blood of horses, dogs, and cats. Am. J. Vet. Res. 62:1755-1760.

Brune, K. 1990. Is there a rational basis for the different spectra of adverse effects of nonsteroidal anti-inflammatory drugs (NSAIDs)? Drugs 40(Suppl. 5):12-15.

Burvenich, C. 1983. Mammary blood flow in conscious lactating goats in various physiological and pathological (mastitis) conditions. Ph.D. Thesis, Ghent University, Belgium. 
Burvenich, C. 1985. Effect of experimentally induced fever and mastitis on blood circulation of the mammary gland and plasma somatotropin in the lactating goat. Kon. Acad. Geneesk. Belg. 5:341-383.

Burvenich, C., and G. Peeters. 1982. Effect of prostaglandin synthetase inhibitors on mammary blood flow during experimentally induced mastitis in lactating goats. Arch. Int. Pharmacodyn. Ther. 258:128-137.

Burvenich, C., G. Vandeputte-Van Messom, and G. Peeters. 1982. Effect of experimentally induced fever on mammary blood flow in lactating goats. Arch. Int. Pharmacodyn. Ther. 259:119-133.

Burvenich, C., G. Vandeputte-Van Messom, E. Roets, A.-M. MassartLeën, and R. Heyneman. 1989. Effects of antagonists of inflammatory mediators on endotoxin induced mastitis in lactating goats. Arch. Int. Physiol. Biochim. 97:47-51.

Burvenich, C., V. Van Merris, J. Mehrzad, A. Diez-Fraile, and L. Duchateau. 2003. Severity of E. coli mastitis is mainly determined by cow factors. Vet. Res. 34:521-564.

DeGraves, F. J., and K. L. Anderson. 1993. Ibuprofen treatment of endotoxin-induced mastitis in cows. Am. J. Vet. Res. 54:11281132.

Dosogne, H., C. Burvenich, T. van Werven, E. Roets, E. N. Noordhuizen-Stassen, and B. Goddeeris. 1997. Increased surface expression of CD11b receptors on polymorphonuclear leukocytes is not sufficient to sustain phagocytosis during Escherichia coli mastitis in early postpartum dairy cows. Vet. Immunol. Immunopathol. 60:47-59.

Dosogne, H., E. Meyer, A. Sturk, J. van Loon, A.-M. Massart-Leën, and C. Burvenich. 2002. Effect of enrofloxacin treatment on plasma endotoxin during bovine Escherichia coli mastitis. Inflamm. Res. 51:201-205.

Dosogne, H., K. Van Oostveldt, A. Diez-Fraile, E. Monfardini, and C. Burvenich. 1999. Decreased aspecific resistance against mastitis of dairy cows during the early post-parturient period. Page 71 in Synthesebrochure Ministerie van Middenstand en Landbouw, Brussels, Belgium.

Edmondson, A. J., I. J. Lean, I. D. Weaver, T. Farver, and G. Webster. 1989. A body condition scoring chart for Holstein dairy cows. J. Dairy Sci. 72:68-78.

Friton, G., H. Phillip, and R. Kleemann. 2002. Efficacy of meloxicam (Metacam) in lactating cows with acute mastitis. Page 27 in Proceedings of XXII World Buiatrics Congress, Hannover, Germany.

Gilroy, D. W., P. R. Colville-Nash, D. Willis, J. Chevers, M. J. PaulClark, and D. A. Willoughby. 1999. Inducible cyclooxygenase may have anti-inflammatory properties. Nat. Med. 5:698-701.

Guha, M., and N. Mackman. 2001. LPS induction of gene expression in human monocytes. Cell. Signal. 13:85-94.

Hill, A. W. 1981. Factors influencing the outcome of Escherichia coli mastitis in the dairy cow. Res. Vet. Sci. 73:985-994.

Hoeben, D., C. Burvenich, E. Trevisi, G. Bertoni, J. Hamann, R. M. Bruckmaier, and J. W. Blum. 2000. Role of endotoxin and TNF$\alpha$ in the pathogenesis of experimentally induced coliform mastitis in periparturient cows. J. Dairy Res. 67:503-514.

Kopcha, M. C., and A. S. Ahl. 1989. Experimental uses of flunixin meglumine and phenylbutazone in food-producing animals. JAVMA 194:45-49.

Kopcha, M., J. B. Kaneene, M. E. Shea, R. Miller, and A. S. Ahl. 1992. Use of non-steroidal anti-inflammatory drugs in food animal practice. JAVMA 201:1868-1872.

Lee, J.-W., M. J. Paape, T. H. Elsasser, and X. Zhao. 2003a. Elevated milk soluble CD14 in bovine mammary glands challenged with Escherichia coli lipopolysaccharide. J. Dairy Sci. 86:2382-2389.

Lee, J.-W., M. J. Paape, T. H. Elsasser, and X. Zhao. 2003b. Recombinant soluble CD14 reduces severity of intramammary infection by Escherichia coli. Infect. Immun. 71:4034-4039.

Lee, J.-W., M. J. Paape, and X. Zhao. 2003c. Recombinant bovine soluble CD14 reduces severity of experimental Escherichia coli mastitis in mice. Vet. Res. 34:307-316.

Lees, P., M. F. Landoni, S. Armstrong, and S. Frean. 2000. New insights into inflammation with particular reference to the role of COX enzymes. Abstract no. A5 in 8th Int. Congr. EAVPT, Jerusalem, Israel.
Lohuis, J. A. C. M., W. van Leeuwen, J. H. M. Verheijden, A. Brand, and A. S. J. P. A. M. van Miert. 1989. Flunixin meglumine and flurbiprofen in cows with experimental Escherichia coli mastitis. Vet. Rec. 124:305-308.

Lohuis, J. A. C. M., T. van Werven, A. Brand, A. S. J. P. A. M. van Miert, B. Ludwig, E. Rohde, P. Heinzmann, and W. F. Rehm. 1991. Pharmacodynamics and pharmacokinetics of carprofen, a non-steroidal anti-inflammatory drug, in healthy cows and cows with Escherichia coli endotoxin-induced mastitis. J. Vet. Pharmacol. Ther. 14:219-229.

Ludwig, B., J. C. Jordan, W. F. Rehm, and R. Thun. 1989. Carprofen in veterinary medicine. I. Plasma disposition, milk excretion and tolerance in milk-producing cows. Schweiz. Arch. Tierheilkd. 131:99-106.

Massart-Leën, A. M., C. Burvenich, G. Vandeputte-Van Messom, and H. Hilderson. 1992. Partial prostaglandin-mediated mechanism controlling the release of cortisol in plasma after intravenous administration of endotoxins. Domest. Anim. Endocrinol. 9:273-283.

Massart-Leën, A. M., G. Vandeputte-Van Messom, and C. Burvenich. 1988. Oxytocin release during experimentally induced fever and inflammation in lactating ruminants. Arch. Int. Physiol. Biochim. 96:43-44.

Monfardini, E., C. Burvenich, A.-M. Massart-Leën, E. Smits, and M. J. Paape. 1999. Effect of antibiotic induced bacterial clearance in the udder on L-selectin shedding of blood neutrophils in cows with Escherichia coli mastitis. Vet. Immunol. Immunopathol. 67:373-384.

Peter, A. T., P. W. Clark, D. E. van Roekel, C. W. Luker, J. D. Gaines, and W. T. Bosu. 1990. Temporal changes in metabolites of prostanoids in milk of heifers after intramammary infusion of Escherichia coli organisms. Prostaglandins 39:451-457.

Petsch, D., and F. B. Anspach. 2000. Endotoxin removal from protein solutions. J. Biotechnol. 76:97-119.

Rainard, P. 2003. The complement in milk and defense of the bovine mammary gland against infection. Vet. Res. 34:647-670.

Rainard, P., P. Sarradin, M. J. Paape, and B. Poutrel. 1998. Quantification of $\mathrm{C} 5 \mathrm{a} / \mathrm{C} 5 \mathrm{a}^{\text {desArg }}$ in bovine plasma, serum and milk. Vet. Res. 29:73-88.

Rantala, M., L. Kaartinen, E. Välimäki, M. Stryrman, M. Hiekkaranta, A. Niemi, L. Saari, and S. Pyörälä. 2002. Efficacy and pharmacokinetics of enrofloxacin and flunixin meglumine for treatment of cows with experimentally induced Escherichia coli mastitis. J. Vet. Pharmacol. Ther. 25:251-258.

Rose, D. M., S. N. Giri, S. J. Wood, and J. S. Cullor. 1989. Role of leukotriene B4 in the pathogenesis of Klebsiella pneumoniaeinduced bovine mastitis. Am. J. Vet. Res. 50:915-918.

Shpigel, N. Y., R. Chen, M. Winkler, A. Saran, G. Ziv, and F. Longo. 1994. Anti-inflammatory ketoprofen in the treatment of field cases of bovine mastitis. Res. Vet. Sci. 56:62-68.

Shpigel, N. Y., M. Winkler, A. Saran, and G. Ziv. 1996. The antiinflammatory drugs fenylbutazone and dipyrone in the treatment of field cases of bovine mastitis. J. Vet. Med. A 43:331-336.

Shuster, D. E., M. E. Kehrli, Jr., P. Rainard, and M. Paape. 1997. Complement fragment C5a and inflammatory cytokines in neutrophil recruitment during intramammary infection with Escherichia coli. Infect. Immun. 65:3286-3292.

Shuster, D. E., M. E. Kehrli, Jr., and M. G. Stevens. 1993. Cytokine production during endotoxin-induced mastitis in lactating dairy cows. Am. J. Vet. Res. 54:80-85.

Shuster, D. E., E. K. Lee, and M. E. Kehrli, Jr. 1996. Bacterial growth, inflammatory cytokine production, and neutrophil recruitment during coliform mastitis in cows within ten days after calving, compared with cows at midlactation. Am. J. Vet. Res. 57:15691575 .

Tobias, P. S., R. I. Tapping, and J. A. Gegner. 1999. Endotoxin interactions with lipopolysaccharide-responsive cells. Clin. Infect. Dis. 28:476-481.

Vandeputte-Van Messom, G., C. Burvenich, E. Roets, A.-M. MassartLeën, R. Heyneman, W. D. J. Kremer, and A. Brand. 1993. Classification of newly calved cows into moderate and severe responders 
to experimentally induced Escherichia coli mastitis. J. Dairy Res. 60:19-29.

Vandeputte-Van Messom, G., R. Reynaert, C. Burvenich, and A. M. Massart-Leën. 1987. Effects of flurbiprofen on endotoxin-induced changes of plasma tyrosine in lactating goats. Arch. Int. Pharmacodyn. Ther. 290:159-160.

Vangroenweghe, F., L. Duchateau, and C. Burvenich. 2004a. Moderate inflammatory response during experimental $E$. coli mastitis in primiparous cows. J. Dairy Sci. 87:886-895.

Vangroenweghe, F., P. Rainard, M. J. Paape, L. Duchateau, and C. Burvenich. 2004b. Increase of Escherichia coli inoculum doses induce faster innate immune response in primiparous cows. J. Dairy Sci. 87:4132-4144.

Verheijden, J. H. M., A. J. H. Schotman, A. S. J. P. A. M. van Miert, and C. T. M. van Duin. 1983. Pathophysiological aspects of Escherichia coli mastitis in ruminants. Vet. Res. Commun. 7:229-236.
Wang, Y., D. S. Zarlenga, M. J. Paape, and G. E. Dahl. 2002. Recombinant bovine soluble CD14 sensitizes the mammary gland to lipopolysaccharide. Vet. Immunol. Immunopathol. 86:115-124.

Wenz, J. R., G. M. Barrington, F. B. Garry, K. D. McSweeney, R. P. Dinsmore, G. Goodell, and R. J. Callan. 2001. Bacteremia associated with naturally occurring acute coliform mastitis in dairy cows. JAVMA 219:976-981.

Wilesmith, J. W., P. G. Francis, and C. D. Wilson. 1986. Incidence of clinical mastitis in a cohort of British dairy herds. Vet. Rec. 22:199-204.

Zia, S., S. N. Giri, J. Cullor, P. Emau, B. I. Osburn, and R. B. Bushnell. 1987. Role of eicosanoids, histamine, and serotonin in the pathogenesis of Klebsiella pneumoniae-induced bovine mastitis. Am. J. Vet. Res. 48:1617-1625.

Ziv, G., and F. Longo. 1991. Comparative clinical efficacy of ketoprofen and flunixin in the treatment of induced E. coli endotoxin mastitis in lactating dairy cows. Pages 207-208 in Mammites des vaches laitières, Société Française de Buiatrie, Paris, France. 